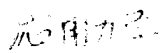 \\ 部分的に固定された辺を有する単純支持 \\ 矩形恷の曲げについで
}

$\begin{array}{lllll}\text { 正員 } & \text { 倉 } & \text { 田 } & \text { 宗 } & \text { 章* } \\ \text { 准員 } & \text { 波 } & \text { 多野 } & \text { 昭 } & \text { 吾** }\end{array}$

\section{BENDING OF A SIMPLY SUPPORTED PLATE HAVING CLAMPED PORTIONS OF EDGE}

By Dr. Eng., Muneaki Kurata, C.E. Member, and Shogo Hatano, C.E. Assoc. Member

Synopsis : In actual structures we are sometimes encountered with plates having such an edge that the type of supporting is varied within the portions. It would seem that such kinds of mixed boundary value problems are not so often handled.

The solution of a problem of this type is reported in this paper. The simply supported. rectangular plate which is clamped partially and symmetrically along the two opposite edges and subjected to some symmetric loads is considered. Some numerical results are shown about a square plate under a uniform load or a point load, whose clamped portions of the edges amount to half a length of these edges.

要 旨 矩形平板の曲げ問題は, 周辺条件の様々な組合せに対して多くの研究があるが一辺の中途に 扣いて支持条件の変るようなものは見かけない様である。実際構造物に批いては支持条件の不完全性又 は特殊な構造部分飞招いて上記の如き周辺状態となつている場合がある様である。このようなるのの解 法の一つの試みとして標題の如き場合を取扱つてみた。本文では簡単の為周辺単純支持の矩形板につき その相対する一対の辺が 対称的に部分固定された場合の対称曲げに対する 解式を導き二, 三の数值的結 果を挙げてこのような板の特異性を示したものである。

\section{1. 基本解式}

図-1 板と座標系

考学る板及び座標系を図一1 亿示すようととる。即ち， $x= \pm \frac{a}{2}$ なる相 対二辺に招いて対称的に部分固定されているものとし，これらの固定部 分，単純支持部分につきそれぞれ図示の如く領域を分け(1)，(2)とする。

i）部分(1)対して用うべき解式一—ず相隣る二辺がそれぞれ $a$ ， $\frac{b}{2}$ なる矩形板を考光 $y=\frac{b}{2}$ なる辺と扔いて

$$
\begin{aligned}
& \text { 線 荷 重 } ： \underset{\substack{m \\
(1,3,5 \cdots)}}{\sum} p_{m} \cos \frac{m \pi x}{a} \text {, } \\
& \text { 分布モーメント： } \underset{\substack{m \\
(1,3,5 \cdots)}}{\sum} M_{m} \cos \frac{m \pi x}{a}
\end{aligned}
$$

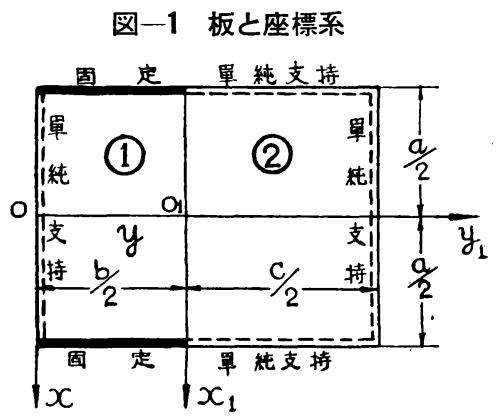

を受け残りの三辺単純支持なる板のたわみを $w_{1}$ とすればこれは容易に求められて次式で与えられる。

但し

$$
w_{1}=\frac{a^{2}}{D \pi^{2}} \sum_{\substack{m \\(1,3,5 \cdots)}}\left[p_{m} f_{m}(y)-M_{m} g_{m}(y)\right] \cos \frac{m \pi x}{a}
$$

$$
\begin{aligned}
& f_{m}(y)=\frac{1}{m^{2} \varepsilon_{m}}\left\{\frac{a \varepsilon_{m}^{\prime}}{(1-\nu) m \pi} \sinh \frac{m \pi y}{a}-y \sinh \beta_{m} \cosh \frac{m \pi y}{a}\right\} \\
& g_{m}(y)=\frac{1}{m^{2} \varepsilon_{m}}\left\{\frac{1+\nu}{1-\nu} \cosh \beta_{m} \sinh \frac{m \pi y}{a}-\beta_{m} \sinh \beta_{m} \sinh \frac{m \pi y}{a}+\frac{m \pi y}{a} \cosh \beta_{m} \cosh \frac{m \pi y}{a}\right\}
\end{aligned}
$$




$$
\begin{aligned}
& \varepsilon_{m}=(3+\nu) \sinh \beta_{m} \cosh \beta_{m}+(1-\nu) \beta_{m} \\
& \varepsilon_{m}{ }^{\prime}=2 \sinh \beta_{m}+(1-\nu) \beta_{m} \cosh \beta_{m} \\
& \beta_{m}=\frac{m \pi b}{2 a}, D=\text { 板の曲げ剛度, } \nu=\text { ポアソン比 }
\end{aligned}
$$

次に相隣る二辺が $a, b$ なる四辺単純支持の矩形板が $x= \pm \frac{a}{2}$ なる相対二辺に扔いて $y=\frac{b}{2}$ 線と対して対称分 布をなす。

$$
\text { 分布モーメント }: \sum_{\substack{n \\(1,3,5 \cdots)}} E_{n} \sin \frac{n \pi y}{b}
$$

を受ける場合のたわみ $w_{2}$ は熟知の次式で与えられる゙2。

$$
\begin{aligned}
w_{2}=\frac{b^{2}}{2 \pi^{2} D} \sum_{\substack{n \\
(1,3,5 \cdots)}} \frac{\sin \frac{n \pi y}{b}}{n^{2} \cosh \alpha_{n}} E_{n}\left(\alpha_{n} \tanh \alpha_{n} \cosh \frac{n \pi x}{b}-\frac{n \pi x}{b} \sinh \frac{n \pi x}{b}\right) \cdots \\
\quad \text { 但し } \alpha_{n}=\frac{n \pi a}{2 b}
\end{aligned}
$$

後の計算の便宁のため上式右辺括弧内を余弦奇数級数に展開しておく。即ち，

$$
\begin{gathered}
w_{2}=\frac{4 a^{2}}{\pi^{3} D} \sum_{\substack{n \\
(1,3,5 \cdots)}} E_{n} \sin \frac{n \pi y}{b} \sum_{\substack{m \\
(1,3,5 \cdots)}} \frac{m(-1)^{\frac{m-1}{2}}}{\rho_{m n}{ }^{2}} \cos \frac{m \pi x}{a} \\
\quad \text { 但し } \rho_{m n}=m^{2}+\frac{a^{2}}{b^{2}} n^{2}
\end{gathered}
$$

更に $x= \pm \frac{a}{2}$ の辺に沿つて固定され残りの相対二䢌 $y=0, y=b$ で単純支持された板が荷重を載せた場合のた わみは容易に求められこれを $w_{0}$ とする。本文と扔いては $x$ 方向の対称曲げを取扱つているのであるから当然荷 重も $x$ 方向に対称分布するもののみを考学る訳であるが，y 方向には任意分布で差支えない。しかし解法の便宜 上,所与の荷重を領域(1), (2)境界線で分割し(1)上の部分荷重を $2 コ, y=\frac{b}{2}$ 線に関し対称に突合せ並べた形の荷 重を仮想し，これを以て $w_{0}$ を与える荷重とする。しかる時は $w_{0}$ は一般に次の形に表わされる。

$$
w_{0}=\frac{1}{D} \sum_{\substack{n \\(1,3,5 \cdots)}} V_{n}(x) \sin \frac{n \pi y}{b}
$$

例えば分布強度 $q$ なる等布荷重の場合には上式中 $V_{n}(x)$ は次の形をとる”。

$$
\begin{aligned}
V_{n}(x)=\frac{4 q b^{4}}{\pi^{5}} \cdot \frac{1}{n^{5} R_{n}}\left\{R_{n}-\left(\alpha_{n}+\tanh \alpha_{n}\right) \frac{\cosh \frac{n \pi x}{b}}{\cosh \alpha_{n}}+\tanh \alpha_{n} \frac{\frac{n \pi x}{b} \sinh \frac{n \pi x}{b}}{\cosh \alpha_{n}}\right\} \\
\text { ここに } R_{n}=\alpha_{n}-\tanh \alpha_{n}\left(\alpha_{n} \tanh \alpha_{n}-1\right)
\end{aligned}
$$

な扮後の計算の便宜の為上式を余弦奇数級数に展開して括かなくてはならない。即ち

$$
V_{n}(x)=\frac{16 q b^{4}}{\pi^{6}} \frac{1}{n^{5} R_{n}} \sum_{\substack{m \\(1,3,5 \cdots)}} \frac{m(-1)^{\frac{m-1}{2}}}{\rho_{m n}} S_{m n} \cos \frac{m \pi x}{a}
$$

但し

$$
S_{m n}=\frac{R_{n} \rho_{m n}}{m^{2}}-\alpha_{n} \operatorname{sech}^{2} \alpha_{n}-\frac{m^{2}+3 \frac{a^{2} n^{2}}{b^{2}}}{\rho_{m n}} \tanh \alpha_{n},
$$

又もし板中央点に集中荷重 $P$ が載つている場合を考えるならば，同様にして次式をうる。

$$
\begin{gathered}
V_{n}(x)=\frac{4 P a^{3}}{\pi^{4} b}(-1)^{\frac{n-1}{2}} \sum_{\substack{m \\
(1,3,5 \cdots)}} \frac{1}{\rho_{m n}^{2}}\left(1-\frac{8 a}{\pi b} \frac{m^{2} n}{\rho_{m n^{2} \delta_{n}}}\right) \cos \frac{m \pi x}{a} \\
\text { ここに } \quad \delta_{n}=\tanh \alpha_{n}+\frac{\alpha_{n}}{\cosh ^{2} \alpha_{n}}
\end{gathered}
$$

以上三種の式を重ね合せ $w_{1}+w_{2}+w_{0}$ を以て部分(1) と対する撓度式とするのであるが $w_{0}$ は当初より $x= \pm \frac{a}{2}$ で固定の条件, 即ち $-\frac{\partial w_{0}}{\partial x}=0$ を満足しているからなお $y$ そ無関係に 


$$
\left|\frac{\partial w_{1}}{\partial x}+\frac{\partial w_{2}}{\partial x}\right|_{x= \pm \frac{a}{2}}=0
$$

が成りたたねばならない。よつてこれに（1)，(2) 式を代入し

$$
\begin{aligned}
f_{m}(y) & =\frac{4 b}{m^{2} \pi^{2} \varepsilon_{m}} \sum_{\substack{n, 3,5 \cdots) \\
\rho_{n m}}} \frac{(-1)^{\frac{n-1}{2}} \phi_{m n} \sin \frac{n \pi y}{b},}{g_{m}(y)}=\frac{4 b}{m \pi a \varepsilon_{m}} \sum_{(1,3,5 \ldots)} \frac{(-1)^{\frac{n-1}{2}}}{\rho_{n m}} \psi_{m n} \sin \frac{n \pi y}{b}
\end{aligned}
$$

と展開出来る事を考慮すると (2) 式中の $E_{n}$ は次の様に定められる。

$$
\begin{aligned}
& \left.E_{n}=-(-1)^{\frac{n-1}{2}} n \frac{8 a}{\pi \delta_{n}} \sum_{\substack{m, 3,5 \ldots) \\
\rho_{n m} \varepsilon_{m}}} \frac{(-1)^{\frac{m-1}{2}}}{\rho_{m n}} p_{m}-\frac{\phi_{m n}}{a} M_{m}\right) \\
& \phi_{m n}=\beta_{m}+\left\{\frac{2}{1-\nu}-\frac{n^{2}-\frac{b^{2} m^{2}}{a^{2}}}{\rho_{n m}}\right\} \sinh \beta_{m} \cosh \beta_{m} \\
& \psi_{m n}=\frac{2}{1-\nu} \frac{n^{2}+\nu \frac{b^{2} m^{2}}{a^{2}}}{\rho_{n m}} \cosh ^{2} \beta_{m} \\
& \rho_{n m}=n^{2}+\frac{b^{2}}{a^{2}} m^{2}
\end{aligned}
$$

但し

又, $w_{1}+w_{2}+w_{0}$ は明らかて $y=0$ で単純支持の条件を満足している。

ii）部分(2)に対して用うべき解式—この部分に対しては 図一1 と示す如き座標軸 $x_{1}, y_{1}$ を用いる事とする。

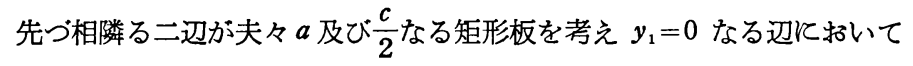

$$
\begin{aligned}
& \text { 線 荷 重: }-\underset{\substack{m \\
(1,3,5 \ldots)}}{\sum_{m}} p_{m} \cos \frac{m \pi x_{1}}{a} \\
& \text { 分布モーメント }: \underset{\substack{m \\
(1,3,5 \cdots)}}{M_{m}{ }^{\prime} \cos \frac{m \pi x_{1}}{a}}
\end{aligned}
$$

を受け残りの三辺単純支持なる板のたわみを $\overline{\boldsymbol{w}}_{1}$ とすればこれは周辺条件の類似性により先に求めた $w_{1}$ の表式よ

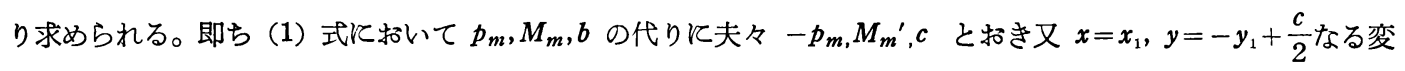
換を施せばよい。結局次式をうる。

$$
\overline{\boldsymbol{w}}_{1}=\frac{a^{2}}{\pi^{2} D} \sum_{(1,3,5 \cdots)}\left[-p_{m} h_{m}\left(y_{1}\right)+M_{m}{ }^{\prime} k_{m}\left(y_{1}\right)\right] \cos \frac{m \pi x_{1}}{a} .
$$

但乙 $h_{m}\left(y_{1}\right)=\frac{a}{m^{3} \pi \mu_{m}}\left[\left\{\gamma_{m}\left(\tanh \gamma_{m}-\operatorname{coth} \gamma_{m}\right)-\frac{2}{1-\nu}\right\} \sinh \frac{m \pi y_{1}}{a}+\frac{2}{1-\nu} \tanh r_{m} \cosh \frac{m \pi y_{1}}{a}\right.$

$$
\begin{aligned}
& \left.\quad-\frac{m \pi y_{1}}{a} \tanh \gamma_{m} \sinh \frac{m \pi y_{1}}{a}+\frac{m \pi y_{1}}{a} \cosh \frac{m \pi y_{1}}{a}\right] \\
& k_{m}\left(y_{1}\right)=\frac{1}{m^{2} \mu_{m}}\left[\frac{1+\nu}{1-\nu} \operatorname{coth} \gamma_{m} \sinh \frac{m \pi y_{1}}{a}+\frac{2-\mu_{m}}{1-\nu} \cosh \frac{m \pi y_{1}}{a}-\frac{m \pi y_{1}}{a} \sinh \frac{m \pi y_{1}}{a}\right. \\
& \left.\quad+\frac{m \pi y_{1}}{a} \operatorname{coth} \gamma_{m} \cosh \frac{m \pi y_{1}}{a}\right] \\
& \mu_{m}=(3+\nu)+(1-\nu) \frac{r_{m}}{\cosh r_{m} \sinh \gamma_{m}} \\
& r_{m}=\frac{m \pi c}{2 a}
\end{aligned}
$$

次に $x_{1}= \pm \frac{a}{2}, y_{1}= \pm \frac{c}{2}$ で単純支持された周辺を有する相隣る二辺がそれぞれ $a, c$ なる矩形板を考兄，これ が荷重を載せた場合のたわみを $\bar{w}_{0}$ とする。この場合も荷重は $x_{1}$ 方向に対称分布をするすののみであるが, $y_{1}$ 方 向には所与の荷重において領域(2)上にある部分荷重を 2 コ， $x_{1}$-軸に関し対称に乫合せ並べた形の荷重を仮想し， これを以て $\bar{w}_{0}$ を与える荷重とする。しかる時は $\bar{w}_{0}$ は一般に次の形に表わされる。 


$$
\bar{w}_{0}=\frac{1}{D} \sum_{\substack{n \\(1,3,5 \cdots)}} \bar{V}_{n}\left(x_{1}\right) \cos \frac{n \pi y_{1}}{c}
$$

上式中 $\bar{V}_{n}\left(x_{1}\right)$ は等分布荷重 $q$ の場合は熟知の如く4

$$
\begin{aligned}
\bar{V}_{n}\left(x_{1}\right)=\frac{4 q c^{4}}{\pi^{5}} & \frac{(-1)^{\frac{n-1}{2}}}{n^{5}}\left\{1-\frac{\bar{\alpha}_{n} \tanh \bar{\alpha}_{n}+2}{2 \cosh \bar{\alpha}_{n}} \cosh \frac{n \pi x_{1}}{c}+\frac{1}{2 \cosh \bar{\alpha}_{n}} \frac{n \pi x_{1}}{c} \sinh \frac{n \pi x_{1}}{c}\right\} \cdots(6)^{\prime} \\
& \text { ここに } \quad \bar{\alpha}_{n}=\frac{n \pi a}{2 c}
\end{aligned}
$$

前同様余弦級数に展開したものは (Navier の解)

$$
\begin{aligned}
\bar{V}_{n}\left(x_{1}\right)= & \frac{16 q a^{4}}{\pi^{6} n}(-1)^{\frac{n-1}{2}} \sum_{\substack{m \\
(1,3,5 \cdots)}} \frac{(-1)^{\frac{m-1}{2}}}{m \bar{\rho}_{m n}{ }^{2}} \cos \frac{m \pi x_{1}}{a} . . \\
& \text { 但し } \quad \bar{\rho}_{m n}=m^{2}+\frac{a^{2}}{c^{2}} n^{2}
\end{aligned}
$$

又中央点に集中荷重 $P$ が載つている場合は5)

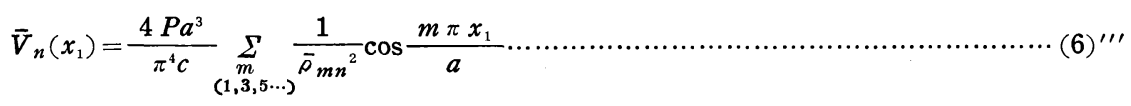

さて (5)，(6) の二式を重㸚せ $\bar{w}_{1}+\bar{w}_{0}$ を以て部分(2に対する撓度式とすれば $x_{1}= \pm \frac{a}{2}, y_{1}=\frac{c}{2}$ の三辺で単 純支持の条件は満されている。

\section{2. 連続の条件}

前節で誘導した(1)，(2)両部分飞対する解式が両者の接続線に沿つて，即ち $y=\frac{b}{2}, y_{1}=0 て ゙$ 連続の条件を満足す る如く解式中の未定常数 $p_{m}, M_{m}, M_{m}{ }^{\prime}$ を決定出来れば解式は完全に決定する訳である。連続の条件は次の 4 つで ある。

1）撓度は連続する。即ち $x\left(=x_{1}\right)$ 飞無関係に次式が成立たねばならぬ。

$$
\left|w_{1}+w_{2}+w_{0}\right|_{y=\frac{b}{2}}=\left|\bar{w}_{1}+\bar{w}_{0}\right| y_{1}=0
$$

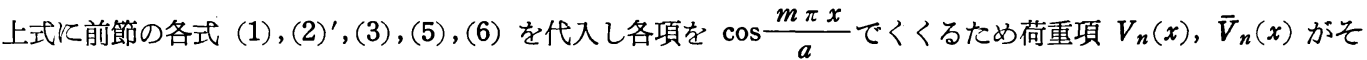
れぞれ余弦級数で

$$
\left.\begin{array}{l}
V_{n}(x)=\frac{a^{3}}{\pi^{2}} \underset{\substack{m \\
(1,3,5 \cdots)}}{\sum} W_{m n} \cos \frac{m \pi x}{a} \\
\bar{V}_{n}(x)=\frac{a^{3}}{\pi^{2}} \sum_{\substack{m \\
(1,3,5 \cdots)}} \bar{W}_{m n} \cos \frac{m \pi x_{1}}{a}
\end{array}\right\}
$$

の形に展開出来るものとすると (7) 式が $x$ そ無関係に成立する為の係数間の関係式が求められ次式をうる。

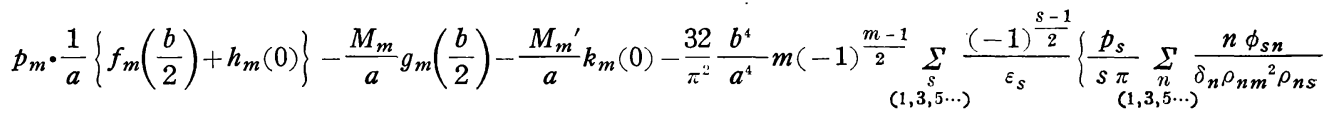

$$
\begin{aligned}
& \left.-\frac{M_{s}}{a} \sum_{\substack{n \\
(1,3,5 \cdots)}} \frac{n \psi_{s n}}{\delta_{n} \rho_{n m}{ }^{2} \rho_{n s}}\right\}=-\underset{\substack{n \\
(1,3,5 \cdots)}}{ }(-1)^{\frac{n-1}{2}} W_{m n}+\underset{\substack{n \\
(1,3,5 \cdots)}}{\bar{W}_{m n}}
\end{aligned}
$$

2) 撓曲面の勾配は連続する。即ち $x\left(=x_{1}\right)$ 飞無関係に

$$
\left|\frac{\partial w_{1}}{\partial \boldsymbol{y}}+\frac{\partial w_{2}}{\partial \boldsymbol{y}}+\frac{\partial w_{0}}{\partial \boldsymbol{y}}\right| y=\frac{v}{2}=\left|\frac{\partial \bar{w}_{1}}{\partial \boldsymbol{y}_{1}}+\frac{\partial \bar{w}_{0}}{\partial \boldsymbol{y}_{1}}\right|_{y_{1}=0}
$$

が成立しなければならない。ところで使用した基本解式の対称性により当初より

$$
\left|\frac{\partial w_{2}}{\partial y}\right|_{y=\frac{b}{2}}=\left|\frac{\partial w_{0}}{\partial y}\right|_{y=\frac{b}{2}}=0, \quad\left|\frac{\partial \bar{w}_{: 1}}{\partial y_{1}}\right|_{y_{1}=0}=0
$$

が成立するから条件式は簡単に

$$
\left|\frac{\partial w_{1}}{\partial y}\right|_{y=\frac{b}{2}=}=\left|\frac{\partial \bar{w}_{1}}{\partial y_{1}}\right|_{y_{1}=0}
$$

と書かれる。従つてこの式に（1），(5) 式を代入して前同様 


$$
\begin{aligned}
& p_{m} \cdot \frac{1}{m^{2}}\left[\frac{1}{\varepsilon_{m}}\left\{\frac{1+\nu}{1-\nu} \sinh \beta_{m} \cosh \beta_{m}+\beta_{m}\right\}+\frac{1}{\mu_{m}}\left\{\gamma_{m}\left(\tanh \gamma_{m}-\operatorname{coth} \gamma_{m}\right)-\frac{1+\nu}{1-\nu}\right\}\right] \\
& -\frac{M_{m}}{a} \frac{2 \pi}{(1-\nu) m \varepsilon_{m}} \cosh ^{2} \beta_{m}-\frac{M_{m}^{\prime}}{a} \frac{2 \pi}{(1-\nu) m \mu_{m}} \operatorname{coth} \gamma_{m}=0 .
\end{aligned}
$$

なる係数間の関係式をろる。

3）曲げモーメントは連続する。即ち $x\left(=x_{1}\right)$ に無関係に

$$
\left|M_{1}+M_{2}+M_{0}\right|_{y=\frac{b}{2}}=\left|\bar{M}_{1}+\bar{M}_{0}\right|_{y_{1}=0}
$$

が成立たねばならない。処で基本解の性質により当初より

$$
\left[M_{1}\right]_{y=\frac{b}{2}}=\sum_{\substack{m \\(1,3,5 \cdots)}} M_{m} \cos \frac{m \pi x}{a},\left[\bar{M}_{1}\right]_{y_{1}=0}=\sum_{m} M_{m}^{\prime} \mathrm{c}_{0} \mathrm{~s} \frac{m \pi x_{1}}{a}
$$

である。その他のモーメントについてはそれぞれの解式を

$$
\begin{gathered}
{\left[M_{2}\right]_{y=\frac{b}{2}}=-D\left\{\frac{\partial^{2} w_{2}}{\partial y^{2}}+\nu \frac{\partial^{2} w_{2}}{\partial x^{2}}\right\} y=\frac{b}{2}, \quad\left[M_{0}\right]_{y=\frac{c}{2}}=-D\left\{\frac{\partial^{2} w_{0}}{\partial y^{2}}+\nu \frac{\partial^{2} w_{0}}{\partial x^{2}}\right\} y=\frac{v}{2}} \\
{\left[\bar{M}_{0}\right] y_{1}=0=-D\left\{\frac{\partial^{2} \bar{w}_{0}}{\partial y_{1}{ }^{2}}+\nu \frac{\partial^{2} \bar{w}_{0}}{\partial x_{1}{ }^{2}}\right\}_{y_{1}=0}}
\end{gathered}
$$

、炕入して計算する。かくてこれ等の表式を用いると前同様係数間の関係式として次式をうる。

$$
\begin{gathered}
\frac{M_{m}}{a}-\frac{M_{m}^{\prime}}{a}-\frac{32 b^{2}}{\pi^{2} a^{2}} m(-1)^{\frac{m-1}{2}} \sum_{\substack{s \\
(1,3,5 \cdots)}} \frac{(-1)^{\frac{s-1}{2}}}{\varepsilon_{s}}\left\{\frac{p_{s}}{s \pi} \sum_{\substack{n \\
(1,3,5 \cdots)}} \frac{n\left(n^{2}+\nu \frac{b^{2} m^{2}}{a^{2}}\right)}{\delta_{n} \rho_{n m} \rho_{n s}} \phi_{s n}\right. \\
\left.\quad-\frac{M_{s}}{a} \sum_{\substack{n \\
(1,3,5 \cdots)}} \frac{n\left(n^{2}+\nu \frac{b^{2} m^{2}}{a^{2}}\right)}{\delta_{n} \rho_{n m^{2} \rho_{n s}}} \psi_{s n}\right\}=-\frac{1}{a} \sum_{\substack{n \\
(1,3,5 \cdots)}}(-1)^{\frac{n-1}{2}} U_{m n}+\frac{1}{a} \underset{\substack{n \\
(1,3,5 \cdots)}}{\sum} \bar{U}_{m n} \cdots
\end{gathered}
$$

但し, $U_{m n}, \bar{U}_{m n}$ は荷重に関する項で前記のモーメント式に解式を代入して得た式を余弦級数に展開した時の Fourier 係数である。即ち $(3),(6),(8)$ の各式を用いて

$$
\begin{aligned}
& {\left[M_{0}\right]_{y=\frac{b}{2}}=\sum_{\substack{n \\
(1,3,5 \cdots)}}(-1)^{\frac{n-1}{2}}\left\{\left(\frac{n \pi}{b}\right)^{2} V_{n}(x)-\nu \frac{\partial^{2} V_{n}(x)}{\partial x^{2}}\right\}=\sum_{\substack{n \\
(i, 3,5 \cdots)}}(-1)^{\frac{n-1}{2}} \sum_{\substack{m \\
(1,3,5 \cdots)}} W_{m n}\left(\frac{n^{2} a^{3}}{b^{2}}+\nu a m^{2}\right) \cos \frac{m \pi x}{a}} \\
& =\underset{\substack{n \\
(1,3,5 \cdots)}}{ }(-1)^{\frac{n-1}{2}} \sum_{\substack{m \\
(1,3,5 \cdots)}} U_{m n} \cos \frac{m \pi x}{a} \\
& {\left[\bar{M}_{0}\right]_{y_{1}=0}=\sum_{\substack{n \\
(1,3,5 \cdots)}}\left\{\left(\frac{n \pi}{c}\right)^{2} \bar{V}_{n}\left(x_{1}\right)-\nu \frac{\partial^{2} \bar{V}_{n}\left(x_{1}\right)}{\partial x_{1}^{2}}\right\}=\sum_{\substack{n \\
(1,3,5 \cdots)(1,3,5 \cdots)}} \sum_{m n} \bar{W}_{m n}\left(\frac{n^{2} a^{3}}{c^{2}}+\nu a m^{2}\right) \cos \frac{m \pi x_{1}}{a}} \\
& =\sum_{n} \sum_{\substack{m \\
(1,3,5 \cdots)(1,3,5 \cdots)}} \bar{U}_{m n} \cos \frac{m \pi x_{1}}{a}
\end{aligned}
$$

これより

$$
U_{m n}=a\left(\frac{n^{2} a^{2}}{b^{2}}+\nu m^{2}\right) W_{m n}, \quad \bar{U}_{m n}=a\left(\frac{n^{2} a^{2}}{c^{2}}+\nu m^{2}\right) \bar{W}_{m n}
$$

4）セン断力及びねじりモーメントは連続する。換言すればいわゆる代用セン断力（Ersatzscherkraft）は連続 する。即ち $x\left(=x_{1}\right)$ と無関係に

$$
\left|R_{1}+R_{2}+R_{0}\right|_{y=\frac{b}{2}}=\left|\bar{R}_{1}+\bar{R}_{0}\right|_{y_{1}=0}
$$

但し, $R_{i}=-D\left\{\frac{\partial^{3} w_{i}}{\partial y^{3}}+(2-\nu) \frac{\partial^{3} w_{i}}{\partial x^{2} \partial y}\right\}, \quad(i=1,2,0) ; \bar{R}_{i}=-D\left\{\frac{\partial^{3} \bar{w}_{i}}{\partial y_{1}{ }^{3}}+(2-\nu) \frac{\partial^{3} \bar{w}_{i}}{\partial x_{1}{ }^{2} \partial y_{1}}\right\}, \quad(i=1,0)$ が成立たねばならない。然るに使用した基本解の対称的性質より

$$
\left|R_{2}\right|_{y=\frac{b}{2}}=\left|R_{0}\right|_{y=\frac{b}{2}}=0, \quad\left|\bar{R}_{0}\right|_{y_{1}=0}=0
$$

が成立するから条件式は簡単となり

$$
\left|R_{1}\right|_{y=\frac{b}{2}}=\left|\bar{R}_{1}\right|_{y_{1}=0}
$$

と書かれる。ところが基本解の性質より当初から 


$$
\left|R_{1}\right|_{y=\frac{b}{2}}=\underset{\substack{m \\(1,3,5 \cdots)}}{\sum} p_{m} \cos \frac{m \pi x}{a}, \quad\left|\bar{R}_{1}\right|_{y 1=0}=\underset{\substack{m \\(1,3,5 \cdots)}}{\sum} p_{m} \cos \frac{m \pi x_{1}}{a}
$$

の関係にあるから上の条件は恒等的に満足されている。

従つて, 以上 4 コの条件式中 3 コ, 即ち $(9),(10),(11)$ の三系の関係式が満足される様に三系の未定常数 $p_{m}$, $M_{m}, M_{m}^{\prime}$ を(計算上は $p_{m}, \frac{M_{m}}{a}, \frac{M_{m}{ }^{\prime}}{a}$,を末定常数として取扱う方が便利)決定出来れば各解式は確定する。 従つてそれ等を重合する事により所与の板の撓度, 其他が求められる訳である。

\section{3. 計 算 例}

実際に数值的結果を検討する為, 正方形板を例にとり $a=b=c$ なる場合を考える。即ち $y$ 軸に平行する相対二 辺に打いて固定区間と単純支持区間の等しい場合である。この場合は $r_{m}=\beta_{m}$ となるから

$$
\mu_{m}=\frac{\varepsilon_{m}}{\sinh \beta_{m} \cosh \beta_{m}}
$$

と書かれ，従つて (10) 式より $M_{m}{ }^{\prime}=-M_{m}$ をうる。故に $p_{m}, M_{m}$ を (9)，(11）の二式より決定すれば良い事 になる。この際,な括

$$
f_{m}\left(\frac{a}{2}\right)=h_{m}(0), \quad g_{m}\left(\frac{a}{2}\right)=-k_{m}(0)
$$

なる関係にあるから結局 (9)，(10) 式は次の如く書かれる。

$$
\begin{aligned}
& p_{m}\left[\frac{2}{a} f_{m}\left(\frac{a}{2}\right)\right]-\frac{M_{m}}{a}\left[2 g_{m}\left(\frac{a}{2}\right)\right]-\frac{32}{\pi^{2}} m(-1)^{\frac{m-1}{2}} \sum_{\substack{s \\
(1,3,5 \cdots)}} \frac{(-1)^{\frac{s-1}{2}}}{\varepsilon_{s}}\left\{\frac{p_{s}}{s \pi} \sum_{\substack{n \\
(1,3,5 \cdots)}} \frac{n \phi_{s n}}{\delta_{n} \rho_{n m}{ }^{2} \rho_{n s}}\right. \\
& \left.-\frac{M_{s}}{a} \sum_{\substack{n \\
(1,3,5 \cdots)}} \frac{n \psi_{s n}}{\delta_{n} \rho_{n m^{2}} \rho_{n s}}\right\}=-\underset{(1,3,5 \cdots)}{\sum}(-1)^{\frac{n-1}{2}} W_{m n}+\underset{(1,3,5 \cdots)}{\sum_{n}} \bar{W}_{m n} \\
& \frac{M_{m}}{a}-\frac{16}{\pi^{2}} m(-1)^{\frac{m-1}{2}} \sum_{\substack{s \\
(1,3,5 \cdots)}} \frac{(-1)^{\frac{s-1}{2}}}{\varepsilon_{s}}\left\{\frac{p_{s}}{s \pi} \sum_{\substack{n \\
(1,3,5 \cdots)}} \frac{n \phi_{s n}}{\delta_{n} \rho_{n m^{2} \rho_{n s}}}\left(n^{2}+\nu m^{2}\right)-\frac{M_{s}}{a} \sum_{\substack{n \\
(1,3,5 \cdots)}} \frac{n \psi_{s n}}{\delta_{n} \rho_{n m} \rho_{n s}}\left(n^{2}+\nu m^{2}\right)\right\} \\
& =-\frac{1}{2 a} \sum_{\substack{n \\
(1,3,5 \cdots)}}(-1)^{\frac{n-1}{2}} U_{m n}+\frac{1}{2 a} \sum_{\substack{n \\
(1,3,5 \cdots)}} \bar{U}_{m n}
\end{aligned}
$$

ここに,

$$
\rho_{n m}=n^{2}+m^{2}=\rho_{m n}, \quad \rho_{n s}=n^{2}+s^{2}
$$

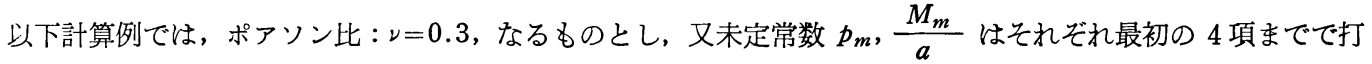
切る事としてその係数を計算し, 且簡単の為

$$
Y_{m}=-\sum_{\substack{n \\(1,3,5 \cdots)}}(-1)^{\frac{n-1}{2}} W_{m n}+\underset{\substack{n \\(1,3,5 \cdots)}}{\sum_{W}} \bar{W}_{m n}, \quad Y_{m}{ }^{1}=-\frac{1}{2 a} \sum_{\substack{n \\(1,3,5 \cdots)}}(-1)^{\frac{n-1}{2}} U_{m n}+\frac{1}{2 a} \sum_{\substack{n \\(1,3,5 \cdots)}} \bar{U}_{m n}
$$

と書けば $(9)_{1}$ 式よりは

$-1.009372 \frac{M_{1}}{a}+0376502 P_{1}-0.025980 \frac{M_{3}}{a}+0.008738 P_{3}+0.009172 \frac{M_{5}}{a}$

$$
-0.002169 P_{5}-0.004617 \frac{M_{7}}{a}+0.000833 P_{7}=Y_{1}
$$

$-0.033616 \frac{M_{1}}{a}+0.014260 P_{1}-0.118327 \frac{M_{3}}{a}+0.018828 P_{3}-0.002821 \frac{M_{5}}{a}$

$$
+0.000467 P_{5}+0.001498 \frac{M_{7}}{a}-0.000204 P_{7}=Y_{3}
$$

$0.011170 \frac{M_{1}}{a}-0.004215 P_{1}-0.003145 \frac{M_{3}}{a}+0.000567 P_{3}-0.043547 \frac{M_{5}}{a}$

$$
+0.020414 P_{5}-0.000843 \frac{M_{1}}{a}+0.000097 P_{7}=Y_{5}
$$

$-0.005197 \frac{M_{1}}{a}+0.001816 P_{1}+0.001770 \frac{M_{3}}{a}-0.000295 P_{3}-0.000908 \frac{M_{5}}{a}$

$$
+0.000113 P_{5}-0.022425 \frac{M_{7}}{a}+0.001562 P_{7}=Y_{7}
$$

又 (11) 1 式よりは 
$1.187987 \frac{M_{1}}{a}-0.078458 P_{1}-0.042676 \frac{M_{3}}{a}+0.008936 P_{3}+0.019977 \frac{M_{5}}{a}$

$$
-0.002818 P_{5}-0.011740 \frac{M_{7}}{a}+0.001271 P_{7}=Y_{1}^{\prime}
$$

$-0.131886 \frac{M_{1}}{a}+0.043017 P_{1}+1.053527 \frac{M_{3}}{a}-0.007446 P_{3}-0.030591 \frac{M_{5}}{a}$

$$
+0.003001 P_{5}+0.019940 \frac{M_{7}}{a}-0.001561 P_{7}=Y_{3}^{\prime}
$$

$0.102967 \frac{M_{1}}{a}-0.030826 P_{1}-0.050977 \frac{M_{3}}{a}+0.006104 P_{3}+1.032415 \frac{M_{5}}{a}$

$$
-0.002699 P_{5}-0.022631 \frac{M_{7}}{a}+0.001500 P_{7}=Y_{5}^{\prime}
$$

$-0.084701 \frac{M_{1}}{a}+0.024353 P_{1}+0.046515 \frac{M_{3}}{a}-0.005118 P_{3}-0.031684 \frac{M_{5}}{a}$

$$
+0.002383 P_{5}+1.023195 \frac{M_{7}}{a}-0.001373 P_{7}=Y_{7}^{\prime}
$$

を得る。これ等の式を 8 元 1 次連立方程式として解く事により $p_{m}, \frac{M_{m}}{a}$ の初めの 4 項計 8 コの未定係数が定め られる訳であるが，応用の便を考虑して各式左辺の係数行列よりその逆行列を求めて反転公式を作ると行列の記 法に従い次の (13) 式を得る。従て荷重項に $W_{m n}, \bar{W}_{m n}, U_{m n}, \bar{U}_{m n}$ を決定して代入する事により直に $p_{m}, \frac{M_{m}}{a}$ が 算出される。

$\left(\begin{array}{c}M_{1} \\ p_{1} \\ \frac{M_{3}}{a} \\ p_{3} \\ \frac{M_{5}}{a} \\ p_{5} \\ \frac{M_{7}}{a} \\ p_{7}\end{array}\right)=\left(\begin{array}{cccccccc}1.0249010 & 0.259497 & -0.0213559 & -0.669651 & 0.0143257 & 0.954412 & -0.0100592 & -1.163017 \\ 2.751305 & 3.448143 & -0.136459 & -3.206457 & 0.0779010 & 4.280036 & -0.0502364 & -5.017497 \\ 0.0149773 & -0.145930 & 0.997658 & 0.502327 & -0.00348325 & -0.867986 & 0.00461466 & 1.189563 \\ -0.156124 & -3.203397 & 6.339787 & 57.934205 & -0.165379 & -13.319255 & 0.129775 & 16.837430 \\ -0.0189769 & 0.105457 & 0.00933243 & -0.399441 & 0.997785 & 0.747761 & -0.000514714 & -1.088708 \\ -0.134794 & 4.272116 & -0.0942139 & -13.313309 & 10.375467 & 248.49179 & -0.174358 & -29.549701 \\ 0.0181931 & -0.0834112 & -0.0116551 & 0.329733 & 0.00517239 & -0.646060 & 0.997822 & 0.973335 \\ 0.424748 & -5.030358 & -0.000664722 & 17.336878 & -0.166509 & -30.149681 & 14.381854 & 659.47931\end{array}\right]\left(\begin{array}{l}Y_{1}^{\prime} \\ Y_{1} \\ Y_{3}^{\prime} \\ Y_{3} \\ Y_{5}^{\prime} \\ Y_{5} \\ Y_{7}^{\prime} \\ Y_{7}\end{array}\right)$

1) 等分布荷重 $q$ を受ける場合一この場合 $W_{m n}$ は (3)" 式と（8）の第 1 式を比較する事により

$$
W_{m n}=\frac{16 q b^{4}}{\pi^{4} a^{3}} \frac{1}{n^{5} R_{n}} \frac{m(-1)^{\frac{m-1}{2}}}{\rho_{m n}} S_{i n n}
$$

を得る。又 $\bar{W}_{m n}$ は (6)" と(8) の第 2 式を比較して

を得る。故に

$$
\bar{W}_{m n}=\frac{16 q a}{\pi^{4} n}(-1)^{\frac{n-1}{2}} \frac{(-1)^{\frac{m-1}{2}}}{m \bar{\rho}_{m n}^{2}}
$$

$$
-\sum_{\substack{n \\(1,3,5 \cdots)}}(-1)^{\frac{n-1}{2}} W_{m n}+\underset{\substack{n \\(1,3,5 \cdots)}}{W_{m n}}=-\frac{16 q a}{\pi^{4}}(-1)^{\frac{m-1}{2}}\left\{m \frac{b^{4}}{a^{4}} \sum_{\substack{n \\(1,3,5 \cdots)}} \frac{(-1)^{\frac{n-1}{2}}}{n^{5} R_{n}} \frac{S_{m n}}{\rho_{m n}}-\frac{1}{m} \underset{\substack{n \\(1,3,5 \cdots)}}{\sum} \frac{(-1)^{\frac{n-1}{2}}}{n \tilde{\rho}_{m n}{ }^{2}}\right\}
$$

と書ける。ところで上式右辺括弧内の第二項の級数は

$$
\sum_{\substack{n \\(1,3,5 \cdots)}} \frac{(-1)^{\frac{n-1}{2}}}{n\left(n^{2}+\lambda^{2}\right)^{2}}=\frac{\pi}{4 \lambda^{4}}\left(1-\frac{1}{\cosh \frac{\pi \lambda}{2}}-\frac{\pi \lambda}{4} \frac{\tanh \frac{\pi \lambda}{2}}{\cosh \frac{\pi \lambda}{2}}\right)
$$

なる総和公式を用いてまとめられるから, 結局

$$
Y_{m}=-\sum_{\substack{n \\(1,3,5 \ldots)}}(-1)^{\frac{n-1}{2}} W_{m n}+\sum_{\substack{n \\(1,3,5 \ldots)}} \bar{W}_{m n}=-\frac{16 q a}{\pi^{4}}(-1)^{\frac{m-1}{2}}\left\{m \frac{b^{4}}{a^{4}} \underset{\substack{n \\(1,3,5 \ldots)}}{\sum} \frac{(-1)^{\frac{n-1}{2}}}{n^{5} R_{n}} \frac{S_{m n}}{\rho_{m n}}\right.
$$




$$
\left.-\frac{\pi}{4 m^{5}}\left(1-\frac{1}{\cosh \gamma_{m}}-\frac{r_{m} \tanh \gamma_{m}}{2 \cosh \gamma_{m}}\right)\right\}
$$

となる。故に只今の例では $a=b=c, r_{m n}=\beta_{m n}$ なる事を考虑して上式を計算すれば

$$
\begin{array}{ll}
Y_{1}=0.0234359 q a, & Y_{3}=-0.00276694 q a, \\
Y_{5}=0.000671321 q a, & Y_{7}=-0.000251988 q a,
\end{array}
$$

を得る。次に $U_{m n}, \bar{U}_{m n}$ は (12) 式に前に求めた $\bar{W}_{m n}, W_{m n}$ を代入して求められる。即ち

同样に

$$
U_{m n}=a\left(\frac{n^{2} a^{2}}{b^{2}}+\nu m^{2}\right) W_{m n}=\frac{16 q b^{2}}{\pi^{4}} \frac{1}{n^{3} R_{n}} \frac{m(-1)^{\frac{m-1}{2}}}{\rho_{m n}} S_{m n}\left(1+\nu \frac{b^{2} m^{2}}{a^{2} n^{2}}\right)
$$

これより

$$
\bar{U}_{m n}=a\left(\frac{n^{2} a^{2}}{c^{2}}+\nu m^{2}\right) \bar{W}_{m n}=\frac{16 q a^{2}}{\pi^{4}}(-1)^{\frac{m-1}{2}} \frac{(-1)^{\frac{n-1}{2}}}{\bar{\rho}_{m n}{ }^{2}}\left(\frac{a^{2} n}{c^{2} m}+\nu \frac{m}{n}\right)
$$

$$
\frac{1}{2 a} \underset{\substack{n \\(1,3,5 \cdots)}}{\sum}(-1)^{\frac{n-1}{2}} U_{m n}=\frac{8 q b^{2}}{\pi^{4} a} m(-1)^{\frac{m-1}{2}} \underset{\substack{n \\(1,3,5 \cdots)}}{\sum} \frac{(-1)^{\frac{n-1}{2}}}{n^{3} R_{n} \rho_{m n}} S_{m n}\left(1+\nu \frac{m^{2} b^{2}}{n^{2} a^{2}}\right)
$$

及び

$\frac{1}{2 a} \sum_{\substack{n \\(1,3,5 \cdots)}} \bar{U}_{m n}=\frac{8 q a}{\pi^{4}}(-1)^{\frac{m-1}{2}} \sum_{\substack{n \\(1,3,5 \cdots)}} \frac{(-1)^{\frac{n-1}{2}}}{\bar{\rho}_{m n}{ }^{2}}\left(\frac{a^{2}}{c^{2}} \frac{n}{m}+\nu \frac{m}{n}\right)=\frac{8 q a}{\pi^{4}}(-1)^{\frac{m-1}{2}}\left\{\frac{a^{2}}{c^{2} m} \underset{\substack{n \\(1,3,5 \cdots)}}{\sum} \frac{n(-1)^{\frac{n-1}{2}}}{\bar{\rho}_{m n}{ }^{2}}+\nu m \underset{\substack{n \\(1,3,5 \cdots)}}{\sum} \frac{(-1)^{\frac{n-1}{2}}}{n \bar{\rho}_{m n}{ }^{2}}\right\}$

を得る。然るに最後の式右辺括弧内の各級数は前出の総和公式及び

なる公式を用いてまとめられて

$$
\underset{\substack{n \\(1,3,5 \cdots)}}{\sum} \frac{n(-1)^{\frac{n-1}{2}}}{\left(n^{2}+\lambda^{2}\right)^{2}}=\frac{\pi^{2}}{16 \lambda} \frac{\sinh \frac{\pi \lambda}{2}}{\cosh ^{2} \frac{\pi \lambda}{2}}
$$

$$
\frac{1}{2 a} \sum_{\substack{n \\(i, 3,5 \cdots)}} \bar{U}_{m n}=\frac{2 q a}{\pi^{3}} \frac{(-1)^{\frac{m-1}{2}}}{m^{2} \cosh r_{m}}\left\{(1-\nu) \frac{\pi b}{4 a} \tanh r_{m}+\frac{\nu}{m}\left(\cosh r_{m}-1\right)\right\}
$$

の様に書かれるから結局,

$$
\begin{aligned}
& Y_{m}^{\prime}=-\frac{1}{2 a} \sum_{(1,3,5 \cdots)}(-1)^{\frac{n-1}{2}} U_{m n}+\frac{1}{2 a} \sum_{\substack{n \\
(1,3,5 \cdots)}} \bar{U}_{m n} \\
& =\frac{2 q a}{\pi^{3}}(-1)^{\frac{m-1}{2}}\left[-\frac{4 b^{2}}{\pi a^{2}} \frac{m}{\rho_{m n}} \underset{(1,3,5 \ldots)}{ } \frac{(-1)^{\frac{n-1}{2}}}{n^{3} R_{n}} S_{m n}\left(1+\nu \frac{m^{2} b^{2}}{n^{2} a^{2}}\right)+\frac{1}{m^{2} \cosh \gamma_{m}}\left\{(1-\nu) \frac{\pi b}{4 a} \tanh \gamma_{m}\right.\right. \\
& \left.\left.+\frac{\nu}{m}\left(\cosh \gamma_{m}-1\right)\right\}\right]
\end{aligned}
$$

前同样 $a=b=c, r_{m n}=\beta_{m n}$ なる事を考慮して計算すると

$$
\begin{array}{ll}
Y_{1}{ }^{\prime}=0.0149476 q a & Y_{3}{ }^{\prime}=-0.00492728 q a \\
Y_{5}{ }^{\prime}=0.00277203 q a & Y_{5}{ }^{\prime}=-0.00194194 q a
\end{array}
$$

を得る。かくて 8 コの常数項が求められたからこれ等を(13) 式に代入すると

$$
\begin{array}{ll}
\frac{M_{1}}{a}=0.024352 q a & p_{1}=0.13593 q a \\
\frac{M_{3}}{a}=-0.010403 q a & p_{3}=-0.28284 q a \\
\frac{M_{5}}{a}=0.0067903 q a & p_{5}=0.33877 q a \\
\frac{M}{a}=-0.0051403 q a & p_{7}=-0.37432 q a
\end{array}
$$

更にこれ等の值を (4) 式に代入して $E_{n}$ を求めると

$$
\begin{array}{ll}
E_{1}=-0.03454 q a^{2} & E_{11}=0.00511 q a^{2} \\
E_{3}=0.01877 q a^{2} & E_{13}=-0.00424 q a^{2} \\
E_{5}=-0.01185 q a^{2} & E_{15}=0.00368 q a^{2}
\end{array}
$$




$$
\begin{array}{ll}
E_{7}=0.00834 q a^{2} & E_{17}=-0.00323 q a^{2} \\
E_{9}=-0.00634 q a^{2} & E_{19}=0.00289 q a^{2}
\end{array}
$$

ここに $E_{n}$ の值は撓度 $w_{2}$ の計算に対しては精々 5 コ程度で十分であるが，曲げモーメントの計算に対しては 級数の収斂が悪くなる為, 可成多数の值が必要となる。ところが $E_{n}$ の值は (4) 式の級数によつて算出されるも ので $n$ の小なる時は容易に計算出来るが， $n$ の值の大となるとつれ極めて収斂の遅い交項級数となり計算困難と なる。然るにかかる交項級数については項毎の差分をとつて急速に収斂する級数に書き直す Euler の変換と称す る総和法を用いれば計算出来るすのである ${ }^{6)}$ 。

上飞求めた未定常数の值を用いて (1), (2), (3), (3)' より $w_{1}+w_{2}+w_{0}$ の值を (5), (6), (6)' よ’り $\bar{w}_{1}+\bar{w}_{0}$ を それぞれ算出して等撓度曲線図を描くと図一2 の如き有様となる。な扔周辺及び板中央点を通る直交二軸に沿つ て曲げモーメントの分布を図示すれば図一 3 亿示す如くであつて，周辺条件の急変するカ所で固定モーメントの

図一2 等分布荷重 $\boldsymbol{q}$ を受ける場合の等撓度曲線図
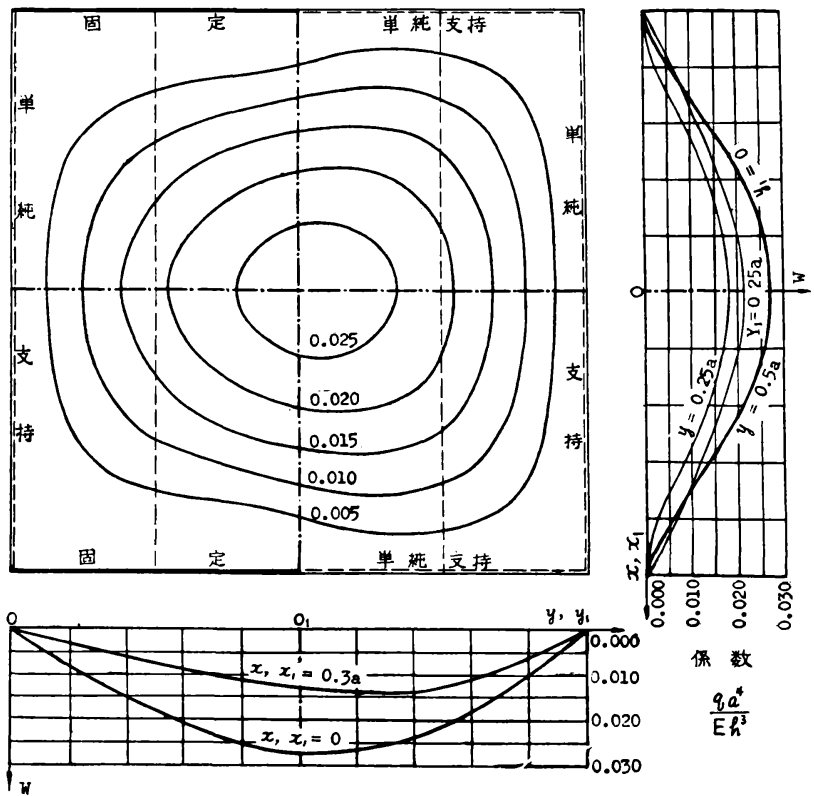

図一3＼cjkstart等分布荷重 $\boldsymbol{q}$ を受ける場合の曲げモーメント図

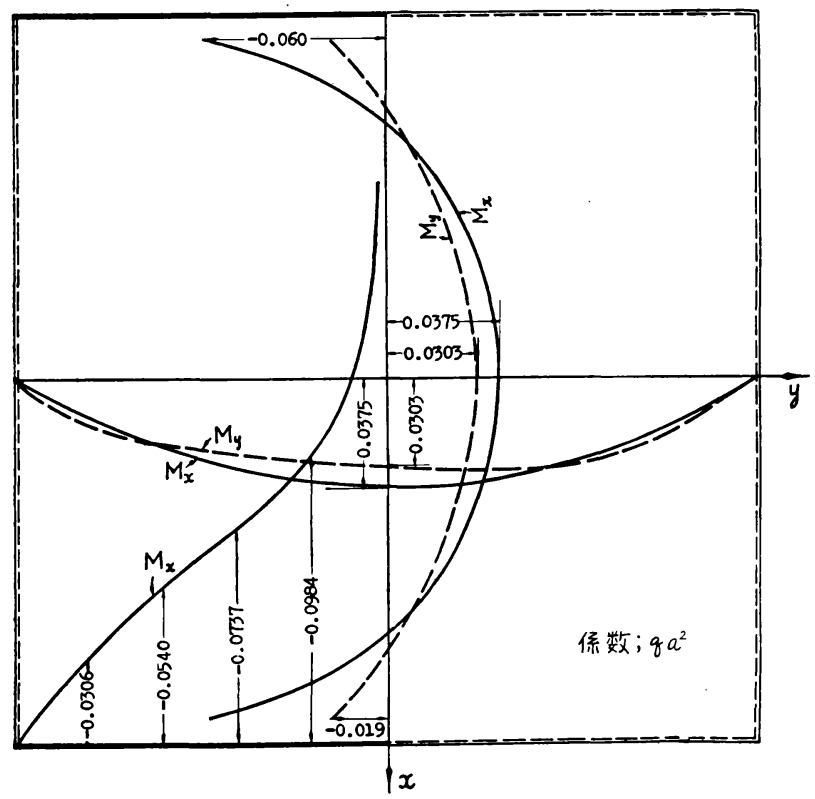


当激な増大が認められる。又曲げモーメントは $y$ 方向， $x$ 方向をそれぞれ $M_{y}, M_{x}$ とすれば

$$
\begin{array}{ll}
M_{y}=-D\left(\frac{\partial^{2}}{\partial y^{2}}+\nu \frac{\partial^{2}}{\partial x^{2}}\right)\left(w_{1}+w_{2}+w_{0}\right), & \bar{M}_{y_{1}}=-D\left(\frac{\partial^{2}}{\partial y_{1}{ }^{2}}+\nu \frac{\partial^{2}}{\partial x_{1}{ }^{2}}\right)\left(\bar{w}_{1}+\bar{w}_{0}\right) \\
M_{x}=-D\left(\frac{\partial^{2}}{\partial x^{2}}+\nu \frac{\partial^{2}}{\partial y^{2}}\right)\left(w_{1}+w_{2}+w_{0}\right), \quad \bar{M}_{x_{1}}=-D\left(\frac{\partial^{2}}{\partial x_{1}{ }^{2}}+\nu \frac{\partial^{2}}{\partial y_{1}{ }^{2}}\right)\left(\bar{w}_{1}+\bar{w}_{0}\right)
\end{array}
$$

で計算されその分布状態を見る為等值曲線を描くと図一4, 図一5 を得る。

図一4 等分布荷重 $\boldsymbol{q}$ を受ける場合の $\boldsymbol{M}_{\boldsymbol{y}}$ 等值曲線図（係数 : $\boldsymbol{q} \boldsymbol{a}^{2}$ )

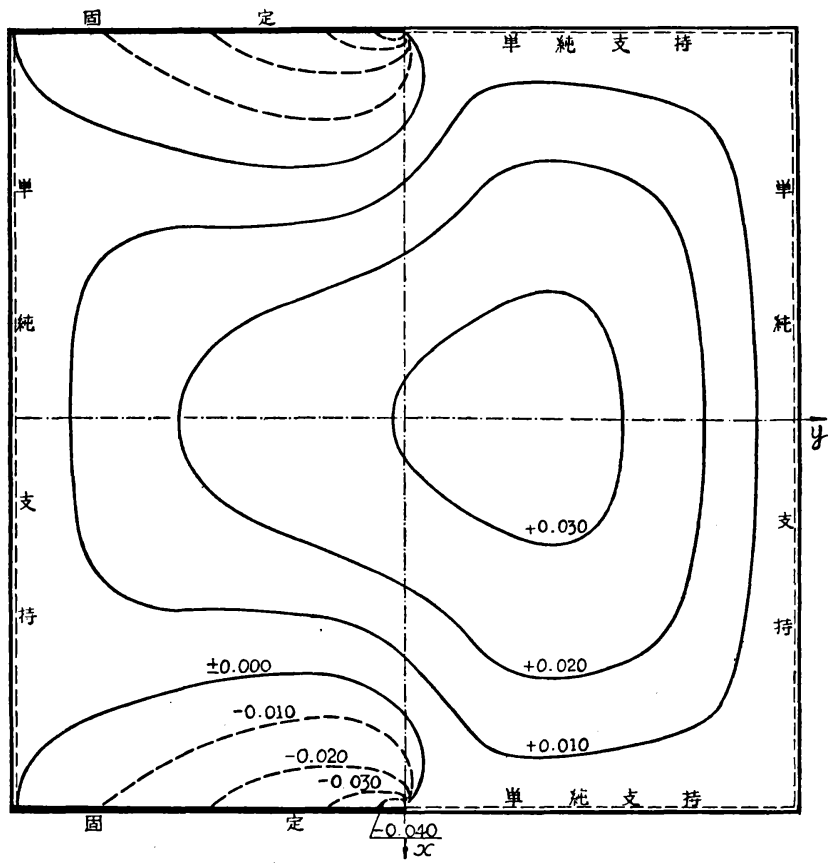

図一5 等分布荷重 $\boldsymbol{q}$ を受ける場合の $\boldsymbol{M}_{\boldsymbol{x}}$ 等值曲線図（係数 $: \boldsymbol{q} \boldsymbol{a}^{2}$ )

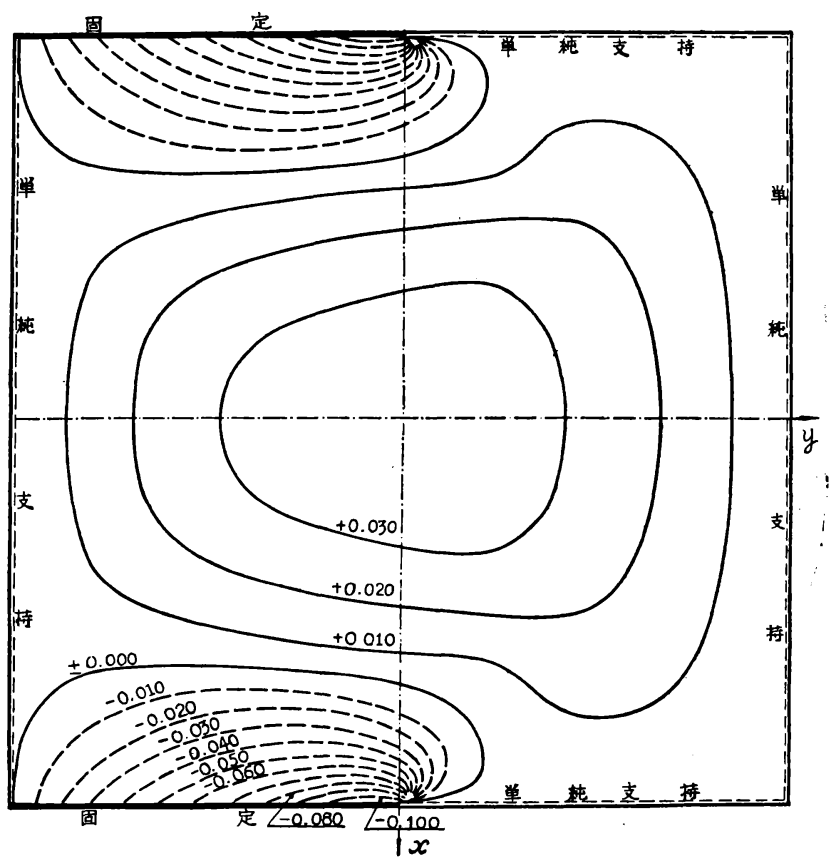

2) 中央点に集中荷重 P を受ける場合一この場合は（3）"' 式と（8）の第 1 式を比較して 


$$
W_{m n}=\frac{4 P}{\pi^{2} b} \frac{(-1)^{\frac{n-1}{2}}}{\rho_{m n}^{2}}\left(1-\frac{8 a}{\pi b} \frac{m^{2} n}{\rho_{m n}{ }^{2} \delta_{n}}\right)
$$

又 $(6)^{\prime \prime \prime}$ と（8）の第2式とを比較して

$$
\bar{W}_{m n}=\frac{4 P}{\pi^{2} c} \frac{1}{\bar{\rho}_{m n}{ }^{2}}
$$

を得る。故に

$$
-\sum_{\substack{n \\(1,3,5 \cdots)}}(-1)^{\frac{n-1}{2}} W_{m n}+\underset{(1,3,5 \cdots)}{\sum} \bar{W}_{m n}=\frac{4 P}{\pi^{2}}\left\{-\frac{1}{b} \sum_{(1,3,5 \ldots)} \frac{1}{\rho_{m n}{ }^{2}}\left(1-\frac{8 a m^{2} n}{\pi b \rho_{m n^{2} \delta_{n}}}\right)+\frac{1}{c} \underset{\substack{n \\(1,3,5 \ldots)}}{\sum} \frac{1}{\bar{\rho}_{m n}{ }^{2}}\right\}
$$

只今の例では $a=b=c, \rho_{m n}=\bar{\rho}_{m n}$ だから上式は簡単となり結局

これを計算すると

$$
Y_{m}=\frac{32 P}{\pi^{3} a} \sum_{\substack{n \\(1,3,5 \ldots)}} \frac{m^{2} n}{\rho_{m n^{4} \delta_{n}}}
$$

$$
\begin{aligned}
Y_{1}=0.0556114 \frac{P}{a} & Y_{3}=0.0011036 \frac{P}{a} \\
Y_{5}=0.0001356 \frac{P}{a} & Y_{7}=0.0000353 \frac{P}{a}
\end{aligned}
$$

を得る。次と前記 $W_{m n}, \bar{W}_{m n}$ を用いて

$$
\begin{aligned}
& U_{m n}=a\left(\frac{n^{2} a^{2}}{b^{2}}+\nu m^{2}\right) W_{m n}=\frac{4 P a}{\pi^{2} b} \frac{(-1)^{\frac{n-1}{2}}}{\rho_{m n}{ }^{2}}\left(1-\frac{8 a}{\pi b} \frac{m^{2} n}{\rho_{m n^{2} \delta_{n}}}\right)\left(\frac{n^{2} a^{2}}{b^{2}}+\nu m^{2}\right) \\
& \bar{U}_{m n}=a\left(\frac{n^{2} a^{2}}{c^{2}}+\nu m^{2}\right) \bar{W}_{m n}=\frac{4 P a}{\pi^{2} c} \frac{1}{\bar{\rho}_{m n}{ }^{2}}\left(\frac{n^{2} a^{2}}{c^{2}}+\nu m^{2}\right)
\end{aligned}
$$

故に

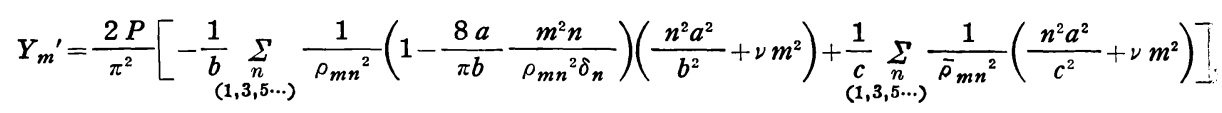

$a=b=c, \rho_{m n}=\bar{\rho}_{m n}$ と扔けば上式は簡単になり

これを計算すると

$$
Y_{m}{ }^{\prime}=\frac{16 P}{\pi^{3} a} \underset{(1,3,5 \cdots)}{\sum_{n=n}} \frac{m^{2} n}{\rho_{m n^{4} \delta_{n}}}\left(n^{2}+\nu m^{2}\right)
$$

$$
\begin{aligned}
Y_{1}{ }^{\prime}=0.0375616 \frac{P}{a} & Y_{3}{ }^{\prime}=0.0037520 \frac{P}{a} \\
Y_{5}{ }^{\prime}=0.0015671 \frac{P}{a} & Y_{7}{ }^{\prime}=0.0006977 \frac{P}{a}
\end{aligned}
$$

以上 8 コの常数項 $Y_{m}, Y_{m}^{\prime}$ を(13) 式に代入すると

$$
\begin{aligned}
\frac{M_{1}}{a} & =0.052213 \frac{P}{a} & p_{1} & =0.29154 \frac{P}{a} \\
\frac{M_{3}}{a} & =-0.0033332 \frac{P}{a} & p_{3} & =-0.097667 \frac{P}{a} \\
\frac{M_{5}}{a} & =0.0063722 \frac{P}{a} & p_{5} & =0.26626 \frac{P}{a} \\
\frac{M_{7}}{a} & =-0.0029839 \frac{P}{a} & p_{7} & =-0.21569 \frac{P}{a}
\end{aligned}
$$

従て前例同様 (4) 式より $E_{n}$ を求めると

$$
\begin{array}{ll}
E_{1}=-0.06196 P & E_{11}=0.00576 P \\
E_{3}=0.02180 P & E_{13}=-0.00481 P \\
E_{5}=-0.01291 P & E_{15}=0.00413 P \\
E_{7}=0.00935 P & E_{17}=-0.00359 P \\
E_{9}=-0.00718 P & E_{19}=0.00316 P
\end{array}
$$

以上の各係数值を用いて等撓度曲線図を描くと図一 6 を得る。

又この場合に対する曲げモーメントの等值曲線図を描くと図一7, 図一8 の如くである。， 
図一6 中央位置に集中荷重 $\boldsymbol{P}$ を受ける場合の等撓度曲線図
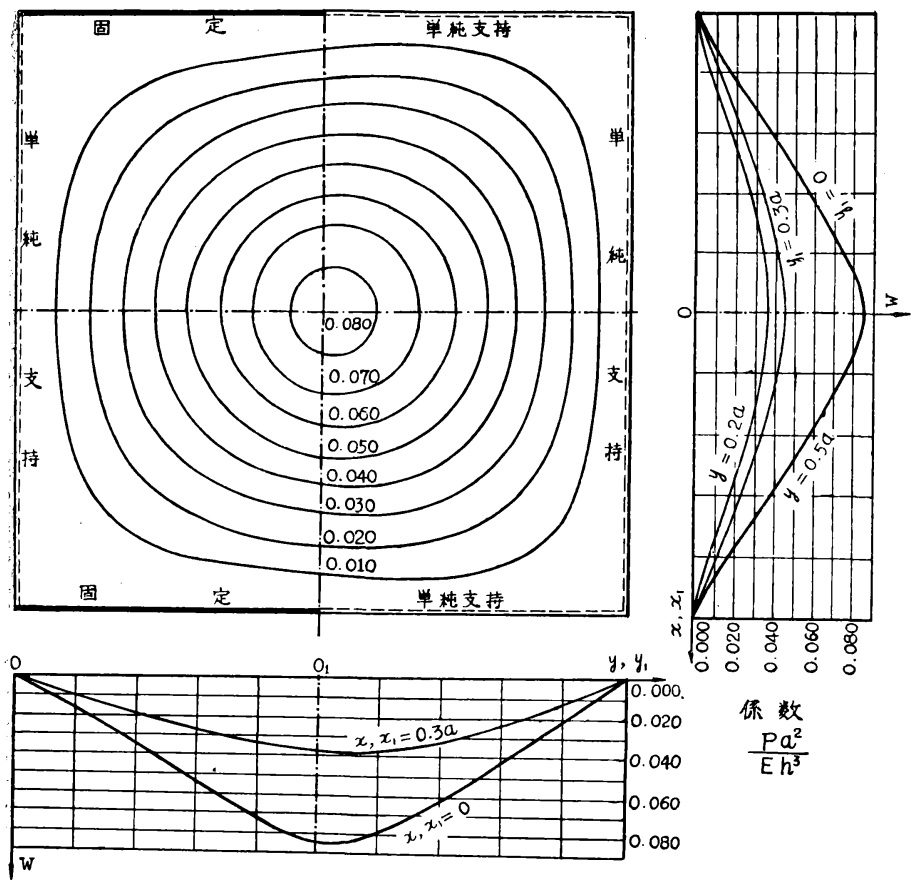

保 数

$\frac{P a^{2}}{E h^{3}}$

図一7 中央位置に集中荷重 $\boldsymbol{P}$ を受ける場合の $\boldsymbol{M}_{\boldsymbol{y}}$ 等值曲線図 (係数 : $\boldsymbol{P}$ )

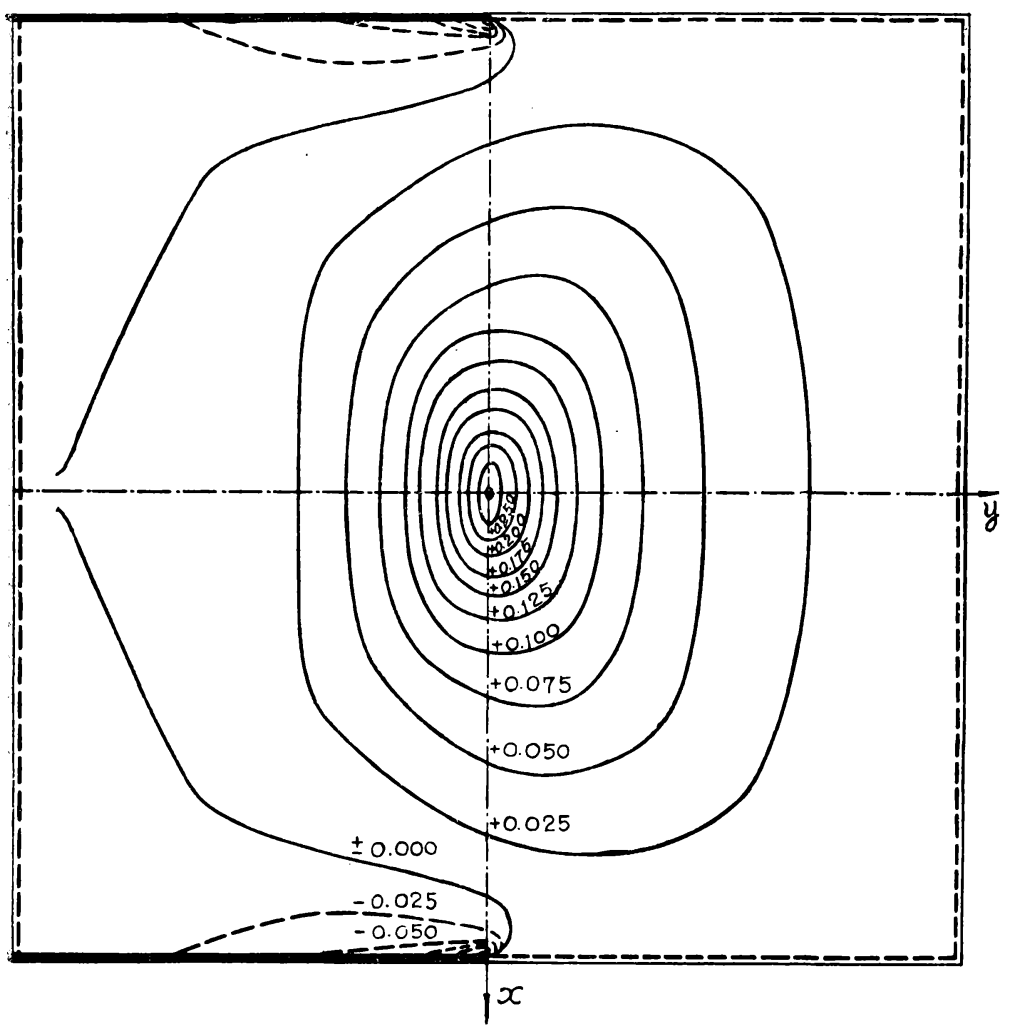


図一8 中央位置に集中荷重 $\boldsymbol{P}$ を受ける場合の $\boldsymbol{M}_{\boldsymbol{x}}$ 等值曲線図（係数 : $\boldsymbol{P}$ )

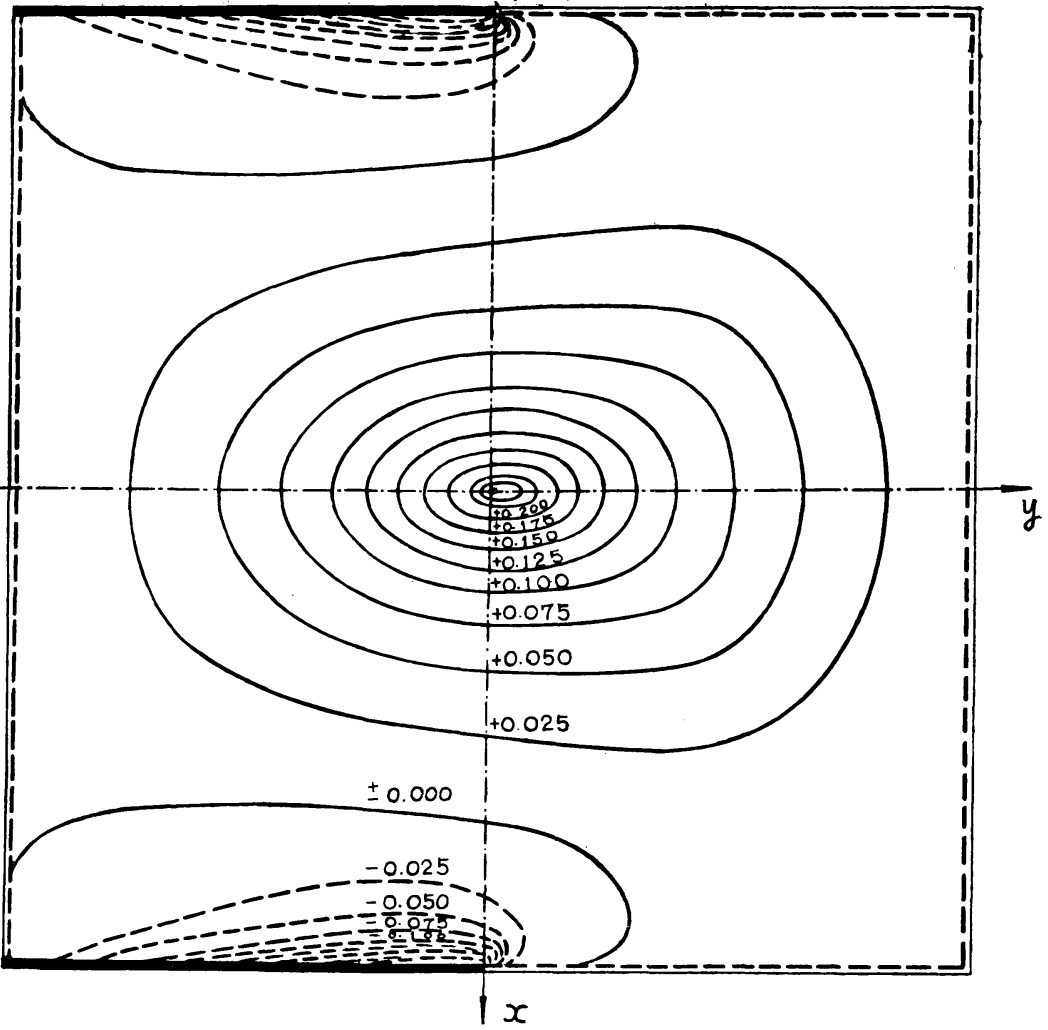

上の二計算例につき板中央点のたわみ及び曲げ モーメントの值を他の熟知の周辺条件をるつ板の 同様な荷重状態の下に括けるそれ等の值と比較し てみると図一9 と示す如くであつて常識的に首肯 しうる範囲にある事が確められる。

\section{むすび}

以上特異な周辺条件を有する矩形板の一例飞就 き一解法を提案し解決の可能性を示したもので， 併せて計算例に示す如き板に対しては他の荷重状 態の場合でる簡単とその数值解を求め得る如き形 そ整頓して解説した。本文では簡単のため専ら $x$ 方向対称荷重による対称曲げを論じたが斜対称荷 重による斜対称曲げも全く同様に論ずる事が出来，

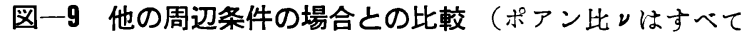
0.3 となすものとす)

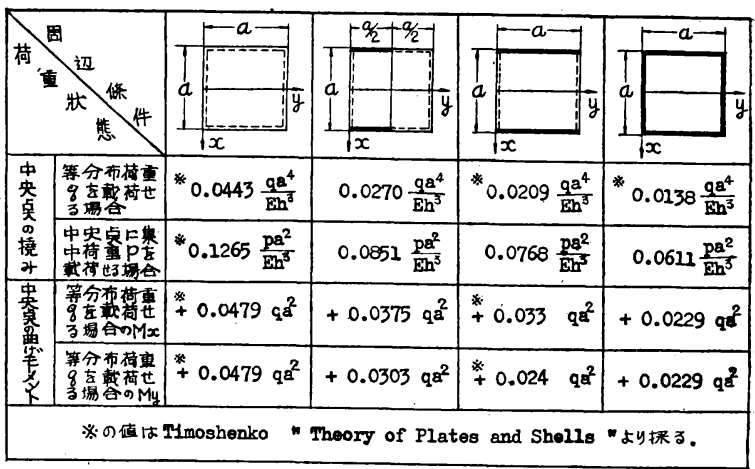
重合によつて得られる事は云うまでもない。

因に本文中に遭遇する如き連立方程式を処理する事は 従来甚だ煩らわしい仕事であつたが 昨今わが国でも高性 能自動計算機の利用が可能となり極めて雑作なく各種の数值を得る事が出来る様になつた事は一つの障壁が取除 かれたものと云うべく，著者もその有難味を体験した。最後に本文は文部省科学研究費による研究の一部なる事 を付記する。

1）第 6 回応用力学連合講演会にて一部発表

参考 文 献

2) S. Timoshenko "Theory of Plates and Shells", Eq. (151), p. 201, 1940

3）同上 pp. 204 207

4) 同 上 Eq.(126), p.128

5）同上 Eq. (125), p.122

6) K. Knopp "Theory and Application of Infinite Series", p.244 London \& Glasgow.

(昭.32.9.11) 